DOI: http://dx.doi.org/10.18569/tempus.v10i3.1914

\title{
Humanização hospitalar e violência simbólica: a percepção das mães em UTIs Neonatais.
}

\section{Hospital humanization and symbolic violence: the perception of mothers in Neonatal ICUs.}

\section{Humanización hospitalaria y violencia simbólica: percepción de madres en las UCIs Neonatales.}

Lívia Ribeiro Vieira ${ }^{1}$

Luiz Antonio Staub Mafra²

RESUMO: O artigo procura situar o processo de humanização no campo das relações de poder e analisa a ocorrência da violência simbólica como agravante da desumanização em hospitais. Para consecução do objetivo, foi realizada pesquisa qualitativa com mães cujos filhos estiveram internados em UTI Neonatal. A partir do resgate da história oral de vida os relatos foram tratados pelo método da Análise de discurso, sendo categorizados em fatores humanizadores e desumanizadores. Os relatos associados aos fatores humanizadores valorizaram o tratamento personalizado e não apenas de acordo com procedimentos técnicos. Quanto aos fatores desumanizadores, além da falta de estrutura física dos hospitais, emergem os relatos de não-acolhimento, de hostilidade e violência simbólica, evidenciando que o processo de humanização passa, sobretudo, pelo estabelecimento de relações menos assimétricas de poder entre a equipe hospitalar e as mães acompanhantes.

Palavras-chave: Política Nacional de Humanização. UTI Neonatal. História Oral de Vida. VIolência Simbólica.

ABSTRACT: This paper aims at the humanization process in the field of power relations and analyzes the occurrence of symbolic violence as an aggravating dehumanization in hospitals. To achieve this objective, a qualitative study was conducted with mothers whose children were admitted to the NICU. From the rescue of oral history of life reports they were treated by the speech analysis method, being categorized in humanizing and dehumanizing factors. The reports associated with humanizing factors appreciated the personalized treatment and not only according to technical procedures. As for the dehumanizing factors, and the lack of physical structure of hospitals, emerging reports of non-acceptance, hostility, and symbolic violence, showing that the process of

1 Mestre em Gestão Pública e Sociedade pela Universidade Federal de Alfenas (UNIFAL). E-mail: ssocial.liviarvvalderramas@gmail.com. ${ }^{2}$ Doutor em Ciências Sociais pela Universidade Federal Rural do Rio de Janeiro (UFRRJ). Professor Adjunto do Instituto de Ciências Sociais Aplicadas (ICSA - UNIFAL). E-mail: lasmafra@gmail.com

2 
humanization implies, above all, the establishment of less asymmetrical power relations between hospital staff and accompanying mothers.

Keywords: National Humanization Policy. Neonatal ICU. Oral History of Life. Symbolic violence.

RESUMEN: Este trabajo tiene como objetivo localizar el proceso de humanización en el campo de las relaciones de poder y analiza la incidencia de la violencia simbólica como una deshumanización agravante en los hospitales. Para lograr el objetivo, la investigación cualitativa se llevó a cabo con las madres cuyos niños fueron ingresados en la UCIN. Desde el rescate de la historia oral de los informes de vida analizados a través del método de análisis del discurso, se categorizaron a los factores en humanización y deshumanización. Los relatos vinculados a factores de humanización apreciaron el tratamiento personalizado y no solo los procedimientos técnicos. En cuanto a los factores deshumanizantes, y la falta de estructura física de los hospitales, se relatan la no aceptación, hostilidad y violencia simbólica, que demuestran que el proceso de humanización implica, sobre todo, el establecimiento de relaciones de poder menos asimétricas entre el personal del hospital y las madres.

Palabras clave: política nacional de humanización; UCIN; historia oral de vida; violencia simbólica.

\section{INTRODUÇÃO}

A humanização em saúde vem ganhando espaço nos debates acadêmicos e nas políticas públicas. Ela reflete a necessidade de reorientar a relação entre a instituição hospitalar e o paciente e, pressupõe ainda, que este seja um processo construído socialmente. Assim, a importância de compartilhar os anseios e expectativas, as experiências e alternativas, são fundamentais para o processo de humanização no atendimento hospitalar, principalmente em momentos de vulnerabilidade física, psíquica e emocional do paciente e da família.

Deslandes (2004) ${ }^{1}$ reforça a compreensão do sentido da humanização como em oposição à violência, seja ela de forma explícita ou simbólica. As formas explícitas abarcam situações nas quais são mais facilmente perceptíveis e podem ser identificadas de forma mais clara, permitindo a adoção de medidas para sua resolução. No entanto, ainda persistem formas de violência simbólica que se expressam na prática hospitalar e que são mais difíceis de serem reconhecidas e, portanto, enfrentadas ou prevenidas.

A introdução de novos recursos preventivos, diagnósticos, e terapêuticos, na área da medicina, possibilitaram significativo aumento da sobrevida de recém-nascidos prematuros, cada vez menores e/ou com comorbidades mais graves ${ }^{2}$, porém também acarretaram a submissão dos neonatos a tratamentos invasivos com alto número de exames e procedimentos.

Com o bebê na UTI Neonatal, a família passa de protagonista à coadjuvante nos cuidados ao Tempus, actas de saúde colet, Brasília, 10(3), 99-114, set, 2016. 
filho. Tocar, pegar no colo, trocar fralda, ou qualquer outro tipo de cuidado é feito pelos profissionais da saúde ou sob sua supervisão. A família está assim sob o poder exercido pelos profissionais que atuam no setor. A relação que se estabelece, a princípio, é a de um elevado conhecimento científico especializado e um desconhecimento generalizado sobre as práticas hospitalares, prognósticos, relatórios, burocracias, termos técnicos, enfim, todo aparato institucional hospitalar para salvaguardar a vida do paciente. Nessa perspectiva, o cenário da UTI pode representar certa hostilidade ao neonato e à família, por sua iluminação artificial, temperatura baixa e equipamentos de alta tecnologia. Nessas unidades, embora o objetivo primordial da equipe seja salvar vidas, os cuidados são centrados no paciente, consequentemente existindo pouca ênfase no suporte emocional à família ${ }^{3}$.

Após o nascimento, o neonato que necessita de suporte imediato, seja em razão da prematuridade ou em função de suas condições clínicas de saúde, é submetido a inúmeros procedimentos invasivos que priorizam a sua sobrevivência fora do útero ${ }^{3}$, mas que também o afastam do acalento materno. Este afastamento pode ocorrer desde poucos dias até meses, representando uma mudança súbita na vida familiar, já que na maioria das vezes a mãe fica como acompanhante do filho durante a internação e separada dos demais membros da família ${ }^{4}$.

As mães de UTI, envolvidas emocionalmente com os filhos, hospitalizados e necessitados de cuidados intensivos, são, na maioria das vezes, as pessoas que estão mais vulneráveis a uma variedade de responsabilidades emocionais e psicológicas para a família que muitas vezes são manifestadas por quadros de choque, ansiedade, raiva, culpa, desespero e medo ${ }^{5}$. O respeito ao usuário dos serviços de saúde como um ser autônomo e digno é visto, como condição fundamental em um processo de humanização ${ }^{6}$. Essa assertiva pressupõe conhecer quem é esse "outro", suas expectativas, suas demandas e prover mecanismos de promover a livre expressão desses usuários, facilitando a verbalização de suas reais demandas.

O presente artigo é parte da dissertação de mestrado História Oral de mães na UTI Neonatal repensando a Política Nacional de Humanização (Pesquisa aprovada pelo Comitê de Ética. Número do CAAE 32269114000005142), e tem como objetivo situar o processo de humanização no campo das relações de poder e enfatizar como a ocorrência da violência simbólica se constitui como um agravamento da desumanização em hospitais.

\section{Humanização, poder e violência simbólica}

A humanização, para Deslandes (2006) e Ayres (2005) é um conceito polissêmico que se refere a reflexões e proposições sobre novas formas de agir, estabelecendo relações mais simétricas entre os sujeitos, por meio das quais o saber formal e científico, as experiências e saberes de pacientes e

3 De acordo com Marshal (1989) ${ }^{35}$, durante o período em que permanecem internados, os prematuros sofrem de 2 a 10 procedimentos invasivos por dia; o que acarreta situações de dor, estresse e desconforto. Barker e Rutter $(1995)^{36}$ afirmam que a maioria dos procedimentos ocorre em prematuros de menor idade gestacional e na primeira semana de vida, sofrendo uma média de 53 a 63 procedimentos invasivos por cada bebê e por internação, chegando a um extremo de 488 procedimentos em um neonato de 23 semanas e $560 \mathrm{~g}$ de peso. 
acompanhantes contribuem para a produção do conhecimento.

Tal conceito lança luz sobre o problema das relações assimétricas entre os sujeitos. Desta forma, há a necessidade de compreendermos a humanização também como relações de poder. Nas UTI's Neonatais, por exemplo, é possível observar a existência de relações de poder assimétricas, nas quais as mães, na maioria das vezes, possuem poucas informações ou conhecimentos sobre a prática hospitalar. Em contrapartida, toda equipe médica possui conhecimentos técnicos e científicos bastante específicos.

Foucault (1979) ${ }^{9}$, afirma que o poder é algo que se exerce, se efetua e se dissemina por toda estrutura social.

Não se explica inteiramente o poder quando se procura caracterizá-lo por sua função repressiva. O que lhe interessa basicamente não é expulsar os homens da vida social, impedir o exercício de suas atividades, e sim gerir a vida dos homens, controlá-los em suas ações, para que seja possível e viável utilizá-los ao máximo, aproveitando suas potencialidades e utilizando um sistema de aperfeiçoamento gradual e contínuo de suas capacidades. Objetivo ao mesmo tempo econômico e político: aumento do efeito de seu trabalho, isto é, tornar os homens força de trabalho, dandolhes uma utilidade econômica máxima; diminuição da sua capacidade de revolta, de resistência, de luta, de insurreição contra as ordens do poder, neutralização dos efeitos de contra-poder, isto é, tornar os homens dóceis politicamente ${ }^{10}$.

O poder é caracterizado por Foucault $(1979)^{9}$ como uma prática social, historicamente constituída, que se encontra em qualquer nível da escala social e pode ser visualizada de forma sutil ou expressa, nos serviços de saúde. Nos diferentes processos que envolvem as atividades cotidianas no hospital, as relações de saber-poder estão presentes e permeiam todos os espaços, gerando relações assimétricas entre os diferentes atores envolvidos pela busca de domínios de espaços, competitividade e conflitos.

Para Deslandes (2004) ${ }^{1}$, o desrespeito à palavra dos pacientes, falta de troca de informações entre paciente-profissional de saúde, a debilidade da escuta e do diálogo são exemplos que geram relações assimétricas entre paciente-profissional de saúde e comprometem a qualidade do atendimento prestado pelos profissionais de saúde.

Foucault (1996) ${ }^{11}$, em "A ordem do discurso", trata da relação entre discurso e poder. Para o autor, há diversas formas de controle ou de exclusão do discurso. As formas de controle externo do discurso, Foucault chama de sistemas de exclusão. Para Foucault (1996) ${ }^{11}$ há três sistemas de exclusão do discurso: interdições, oposição entre razão e loucura, e vontade de verdade.

Essas formas de exclusão exercem sobre os indivíduos uma "espécie de pressão", impedindo ou fazendo com que ele tema em anunciar o discurso. Assim sendo, o discurso desenha-se como uma forma de dominação de um indivíduo sobre outro ${ }^{11}$. Um exemplo é o discurso médico ao 
utilizar-se de uma linguagem técnica é incompreensível para os pacientes.

A humanização em UTIs neonatais e as relações de poder estabelecidas nesse ambiente apresentam algumas particularidades frente à humanização hospitalar em geral, pois o bebê não possui condições de decidir por si próprio e, portanto, precisará do acompanhamento da mãe, ou de outro responsável, para tomar decisões e se co-responsabilizar pelas ações do hospital (ou equipe médica).

Esta relação desigual entre pacientes/familiares e as equipes hospitalares aproxima-se da concepção de Bordieu (2007) ${ }^{12}$, para o qual o poder simbólico se define por meio de relações determinadas entre os que exercem o poder e os que lhe estão sujeitos. Para o autor, o que faz o poder das palavras e das palavras de ordem, poder de manter a ordem ou de a subverter, é a crença na legitimidade das palavras e daquele que as pronuncia.

O poder simbólico no campo da saúde, segundo Pereira $(2004)^{13}$, se estrutura sobre pilares, como a manutenção de um monopólio quase absoluto dos saberes sobre o corpo e as diferentes formas de nele intervir, e a desqualificação do outro enquanto portador de saberes e de direitos sobre o próprio corpo e sobre a saúde.

\section{Humanização e políticas públicas}

Segundo Deslandes (2004)ํㅜ o termo “humanização” é utilizado, há décadas, no âmbito da saúde.

As iniciativas identificadas com a humanização do parto e com o respeito aos direitos reprodutivos das mulheres vêm, há décadas, participando da pauta dos movimentos feministas em saúde. Por sua vez, a humanização da assistência a crianças faz parte de um escopo mais direcionado ao atendimento de bebês de baixo peso, internados em UTI. Alguns modelos de assistência pautados por tal princípio, tais como os projetos Maternidade Segura e o Método Canguru, são amplamente apoiados pelo Ministério da Saúde e pela Organização Mundial de Saúde, e considerados referência para a rede pública ${ }^{1}$.

No entanto, foi apenas no ano 2000, que o Ministério da Saúde, através da regulamentação do Programa Nacional de Humanização da Assistência Hospitalar (PNHAH) conferiu legitimidade ao tema, com a inclusão da humanização na pauta da 11a Conferência Nacional de Saúde, realizada em dezembro do mesmo ano. O objetivo fundamental do PNHAH consistiu em aprimorar as relações entre profissionais, entre usuários/profissionais e entre hospital e comunidade, visando a melhoria da qualidade e à eficácia dos serviços prestados nos hospitais ${ }^{14}$. Em 2003, o PNHAH foi substituído pela Política Nacional de Humanização (PNH), constituindo-se como uma política de assistência que opera em toda rede SUS, não mais um programa específico.

A PNH foi instituída ainda em 2003, tendo como princípios norteadores: a valorização da dimensão subjetiva e social em todas as práticas de atenção e gestão no SUS, fortalecendo o 
compromisso com os direitos do cidadão, destacando-se o respeito às questões de gênero, etnia, raça, orientação sexual e às populações específicas (índios, quilombolas, ribeirinhos, assentados, etc.); fortalecimento de trabalho em equipe multiprofissional, fomentando a transversalidade e a grupalidade; apoio à construção de redes cooperativas, solidárias e comprometidas com a produção de saúde e com a produção de sujeitos; construção de autonomia e protagonismo de sujeitos e coletivos implicados na rede do SUS; corresponsabilidade desses sujeitos nos processos de gestão e de atenção; fortalecimento do controle social com caráter participativo em todas as instâncias gestoras do SUS; compromisso com a democratização das relações de trabalho e valorização dos profissionais de saúde, estimulando processos de educação permanente ${ }^{15}$.

A PNH possui alguns princípios norteadores que devem servir como base para as mudanças na relação entre profissionais e usuários: o acolhimento, a autonomia, o protagonismo e a corresponsabilidade. É uma política que coloca em questão as práticas em saúde, construídas com base no modelo biomédico, principal referencial epistemológico para a formação dos profissionais do campo ${ }^{15}$.

O acolhimento envolve a observação e escuta atenta, capaz de perceber as diversas demandas. Como conceito norteador da $\mathrm{PNH}$, pode ser entendido como princípio voltado para uma reflexão das práticas de saúde, pois reconhece o outro em suas diferenças a partir de um compromisso de responsabilização no encontro terapêutico. Além disso, a PNH toma-o também como dispositivo que opera mudanças concretas nos processos de trabalho e na gestão dos serviços ${ }^{16}$.

No cotidiano de uma enfermaria, um amplo conjunto de fatores envolve os profissionais, pacientes e acompanhantes. Considerar estas redes de relações que envolvem os sujeitos e os valores que os permeiam é uma das reflexões que impacta na construção de uma responsabilização compartilhada e permite entender que o ser humano é um ser dependente de suas redes, e estas são, portanto, importantes para sua saúde ${ }^{16}$.

A autonomia refere-se à capacidade de decisão dos atores baseada em informações, diálogo e valorização da rede de relações que permeiam os indivíduos. É um valor que se constitui de forma relativa e inseparável da dependência entre os sujeitos. Fortalecer a autonomia dos mesmos requer incentivo à rede de relações que os sustentam ${ }^{17}$.

De acordo com Alves, Deslandes e Mitre (2009) ${ }^{16}$, este exercício da autonomia está diretamente relacionado com a qualidade de informação disponibilizada durante o encontro terapêutico, pois na medida em que paciente e acompanhante disponibilizam e compreendem o contexto em que estão inseridos, a autonomia de ambos pode ser exercida de forma mais plena. Compartilhar informações necessárias que envolvem o tratamento permite estabelecer uma participação construtiva no processo terapêutico, possibilitando aos sujeitos a manifestação de sua capacidade protagonista.

Nesse sentido, o acolhimento como princípio base e que possibilita a construção de relações Tempus, actas de saúde colet, Brasília, 10(3), 99-114, set, 2016. 
mais dialógicas, pode facilitar a produção de vínculos, entendendo o usuário como capaz de exercer sua autonomia e sua capacidade protagonista, compartilhando a responsabilidade pelo cuidado ${ }^{16}$.

Benevides e Passos $(2005)^{18}$, afirmam que apesar de ser considerado um inegável avanço a existência da Política Nacional de Humanização em relação ao PNHAH, estes princípios ainda se configuram em ações fragmentadas.

A humanização, expressa em ações fragmentadas e numa imprecisão e fragilidade do conceito, vê seus sentidos ligados ao voluntarismo, ao assistencialismo, ao paternalismo ou mesmo ao tecnicismo de um gerenciamento sustentado na racionalidade administrativa e na qualidade total ${ }^{19}$.

Atualmente, a humanização no Brasil apresenta-se como objeto de leis, diretrizes curriculares e indicativos de controle de qualidade em clínicas e hospitais, além da formação de Comissões de Humanização e treinamento dos profissionais em humanização ${ }^{20}$.B No entanto, a simples existência da PNH, não promove, automaticamente, mudanças estruturais na racionalidade biomédica. Como apontam Lacerda e Valla (2003) ${ }^{21}$, a qualidade da relação médico-paciente é fundamental ao cuidado em saúde. A qualidade dos vínculos, a satisfação durante o processo e a comunicação estabelecida são elementos fundamentais.

Segundo Barra et al $(2005)^{22}$, o paciente possui três tipos de necessidades durante sua hospitalização: conforto emocional, conforto físico e compromisso profissional, com atendimento humanizado. No entanto, a complexidade da rotina intensiva e o domínio tecnológico que reina perante ações individuais, dificulta o processo de humanização; na medida em que contribui para a padronização das ações, em detrimento do atendimento individualizado, conforme preconizado na PNH $(2003)^{15}$.

O atendimento individualizado está descrito na PNH (2003) ${ }^{15}$ como a valorização da dimensão subjetiva e coletiva em todas as práticas de atenção e gestão no SUS, fortalecendo o compromisso com os direitos de cidadania, destacando-se as necessidades específicas de gênero, étnico - racial, orientação/expressão sexual e de segmentos específicos ${ }^{23}$, como, no caso da pesquisa, das mães, acompanhantes de bebês em UTI Neonatal.

\section{A HUMANIZAÇÃO COMO OBJETO DE PESQUISA: ALGUMAS NOTAS METODOLÓGICAS}

A humanização como objeto de pesquisa pode contemplar diversas perspectivas e cada qual revelar a complexidade e a subjetividade envolvidas em seus contextos. No entanto, é importante ressaltar a perspectiva daqueles que sofrem com o que se considera como atendimento "nãohumanizado'.

De modo a permitir que as mães acompanhantes de bebês internados em UTIN (Unidade de Terapia Intensiva Neonatal), tornassem público seus questionamentos, críticas e elogios sobre a 
humanização no cotidiano da UTI, foi realizada pesquisa com seis mães, sendo três de hospital público e três de hospital particular, que tiveram filhos anteriormente internados em UTIN e que participaram de ações de determinada Organização Não-Governamental, especializada no acolhimento de mães com filhos internados em UTIN's, a qual intermediou o contato com as mesmas.

A divisão em dois grupos, hospital público e hospital particular, foi utilizada devido a própria composição do SUS, no setor hospitalar atual. De acordo com La Forgia e Couttolenc

$(2008)^{24}$, o Brasil possui um sistema hospitalar altamente pluralista, composto por uma gama de arranjos financeiros, organizacionais e de propriedade que abrangem tanto o setor público quanto o privado. Todos os hospitais particulares envolvidos na pesquisa também possuem vagas destinadas ao SUS e, portanto, estão sujeitos às normas da PNH (2003).

Para alcançar o objetivo proposto foi utilizada uma abordagem de pesquisa qualitativa.

Segundo Minayo (1992) ${ }^{25}$, a pesquisa qualitativa trabalha com dados subjetivos, crenças, valores, opiniões, fenômenos, hábitos. Além disso, segundo a autora, pesquisa qualitativa se preocupa, nas ciências sociais, com um nível de realidade que não pode ser quantificado, ou seja, ela trabalha com o universo de significados, motivos, aspirações, crenças, valores e atitudes, o que corresponde a um espaço mais profundo das relações dos processos e dos fenômenos que não podem ser reduzidos à operacionalização de variáveis ${ }^{24}$.

Para a construção das narrativas das mães de UTI, recorreu-se à História Oral de Vida, por privilegiar a fala dos sujeitos que participaram ou testemunharam acontecimentos, valorizando a trajetória individual e a experiência das pessoas envolvidas na pesquisa.

Todas as entrevistas foram não-dirigidas (não houve interferência direta da pesquisadora), e previamente agendadas por email ou telefone, e aconteceram em local definido pelas colaboradoras. A finalidade do estudo, informação sobre a gravação da entrevista, leitura e assinatura do TCLE foram realizados antes do início das entrevistas. Todas as mães tiveram a opção de permanecer no anonimato e/ou o nome e/ou sobrenome de seus filhos em sigilo, assim como do hospital no qual estiveram internados. Como a maioria das mães decidiu não revelar o nome da instituição à qual estava se referindo durante a entrevista, nem mesmo para a pesquisadora, não foi possível analisar as características dos mesmos. As entrevistas foram analisadas a partir da técnica de Análise de Conteúdo, como proposta por Bardin $(1977)^{26}$.

Para a realização da Análise de Conteúdo, as categorias de análise utilizadas foram elaboradas em dois momentos distintos. Primeiramente, foram elaboradas categorias de análise a partir das diretrizes da Política Nacional de Humanização ${ }^{15}$, sobre fatores que contribuem para amenizar ou agravar o sofrimento das mães acompanhantes dos bebês internados em UTI's Neonatais, emergindo duas categorias - agrupadas em fatores humanizadores e fatores desumanizadores (Tabela 01). 
No segundo momento, após a realização das entrevistas e de posse do corpus de análise, verificouse a necessidade da criação de subcategorias, que permitissem uma análise mais detalhada. Esse procedimento de elaborar categorias com base no corpus, tendo em vista as especificidades do próprio corpus e as necessidades da pesquisa, é previsto pela metodologia da análise de conteúdo ${ }^{26}$.

$\mathrm{Na}$ categoria "fatores humanizadores" emergiram relatos de situações nas quais as mães destacaram/valorizaram a atenção recebida de acordo com suas especificidades e não apenas segundo protocolos; relatos de situações em que os profissionais de saúde recepcionaram a família, desde a chegada do bebê na UTI Neonatal, informando aos pais todas as etapas dos tratamentos aos quais seus filhos seriam submetidos; e situações em que foram respeitados os direitos da criança conforme preconizado pelo Estatuto da Criança e do Adolescente ${ }^{29}$, no que se refere ao direito de acompanhante, em tempo integral, para a criança e adolescente hospitalizado; sendo agrupados respectivamente em três subcategorias: "atendimento individualizado", "acolhimento", e "respeito aos direitos da criança".

Por fatores desumanizadores foi utilizada como referência a abordagem de Deslandes (2006) na qual considera a desumanização como "a maneira de tratar as pessoas como se tivessem menor valor e de prover cuidados abaixo do padrão, objetos de um mesmo processo de hierarquização e discriminação social, presente nos sistemas de saúde" 7 .

\section{O lugar e as palavras: delimitações de espaços e discursos na construção dos fatores desumanizadores}

Os casos mais emblemáticos da violência simbólica que apareceram nos relatos referem-se às decisões tomadas pelas equipes médicas sem serem compartilhadas com as mães. Nestes casos não houve o acolhimento das famílias, onde as decisões são tomadas em conjunto, após devida informação e esclarecimentos sobre procedimentos clínicos que serão realizados nos pacientes.

Para Machado (1979) $)^{30}$, o não-acolhimento das famílias é estratégico à manutenção do poder médico na instituição, já que os saberes constituem-se como um elemento necessário para as relações de poder e que, o diálogo entre profissional de saúde e usuário, torna-se dispositivo político nas disputas de forças e dominação.

Os relatos abaixo demonstram esta relação de poder que perpassa o saber profissional e a autonomia da mãe para decisões relacionadas ao filho. Faz-se necessário ressaltar que nenhum procedimento citado pelas mães foi realizado em situação de emergência, no qual não há tempo hábil para discussões prévias.

Eu falo assim: [...] a gente vê que TUDO foi realizado sem a nossa autorização! Eu cheguei lá, falaram: "nós fizemos traqueostomia porque ia atrofiar". Não perguntaram: "você quer"? "Fizemos a gastro porque ele tava aspirando". Não falaram assim: “ó temos outras opções[...]”. Me deram o negócio tudo pronto! Cada vez que eu chegava lá, tinha uma novidade e eu tinha que estar preparada! (M2L254) 
Além disso, emergiram os relatos de informações técnicas que não eram possíveis de serem reconhecidas pelas mães. Este fato contribui para o fortalecimento da assimetria de poder na relação entre mãe do paciente e profissional de saúde.

Aí eu questionei demais e aí me falaram: "não, mas no resumo da alta tem uma sigla, tá escrito HIC 2, que é hemorragia intracraniana de grau 2". Mas pra mim isso não significa NADA! (Risos) HIC 2 pra mim não significa[...] nada! Se você não me fala claramente, eu não sou da área médica!(M4L672)

Essa relação de autoridade do profissional de saúde, onde fica nítida a assimetria de poder do profissional de saúde e da mãe do paciente, também foi perceptível em um dos casos de óbito do neonato, onde por determinação da equipe de saúde que cuidava do caso, a mãe não teve oportunidade de se despedir do filho.

E aí quando ligaram do hospital pra eu ir, ela já tinha morrido e até me darem a notícia, me acordarem, levei duas horas pra chegar no hospital. E quando eu cheguei eles já tinham tirado, tirado ela do hospital e levado pro IML, de forma que eu não vi! Eu saí do hospital, ela tava viva, e nunca mais a vi, porque o caixão foi lacrado! (M4L564)

De acordo com Oliveira e Maruyama (2009) $)^{31}$, quando se trata de quem detém o conhecimento clínico, ou seja, o profissional de saúde, este se utiliza dessa ferramenta para manter a sua posição de superioridade na relação profissional-usuário no espaço da UTI. Os indivíduos que precisam de atendimento em saúde, para si ou outrem, sujeitam-se às normas e condutas dos profissionais. Essa realidade não demanda o emprego de violência física, já que o poder se exerce essencialmente pelas vias puramente simbólicas da comunicação e conhecimento, de tal modo que não se possa questionar a legitimidade do poder exercido.

\section{Fatores humanizadores: quebra de protocolo e o reconhecimento do papel e função das} mães

Se num primeiro momento os fatores considerados desumanizadores tiveram uma forte relação a comportamentos da equipe que evidenciam algum tipo de violência simbólica; nos fatores humanizadores emergiram os relatos de comportamentos que contribuem para o processo de humanização. Neste caso, o que chamou a atenção foi a valorização de situações em que houve a quebra de protocolo. As mães evidenciaram situações em que a relação dos profissionais de saúde não foi meramente protocolar, e sim uma relação mais pessoal, onde as condutas profissionais foram tomadas de acordo com as especificidades de cada caso.

De acordo com Klaus e Kennel (1993) ${ }^{32}$, a família do recém-nascido em uma UTIN passa a conviver com equipamentos de alta tecnologia, na maioria das vezes totalmente desconhecidos, com pessoas desconhecidas, o que acaba por configurar um ambiente que muitos consideram assustador. Além disso, segundo os autores, suas relações familiares e suas crenças são minimizadas, devido à própria rotina do serviço que impede a permanência em tempo integral dos pais ao lado 
do filho. Para Klaus e Kennel (1993) ${ }^{32}$, os pais expressam diversos sentimentos durante o período de internação, que pode variar da culpa à preocupação, passando pelo medo, ira e ansiedade, que podem ser agravados, por exemplo, ao presenciarem um procedimento doloroso.

Através dos relatos é possível perceber que as mães valorizaram quando os profissionais da área da saúde romperam as barreiras protocolares referentes aos cuidados básicos serem realizados somente pela equipe de enfermagem, possibilitando condições para que a mãe pudesse pegar o bebê no colo e/ou proporcionassem cuidados aos filhos (troca de fralda, administração do leite pela sonda, dar banho, dentre outros). Estas atitudes contribuíram, de acordo com os relatos, para diminuir o sofrimento causado pela internação do bebê em UTI.

Algumas pessoas eram humanas, e pelo fato delas serem, proporcionavam um ambiente melhor e mais humano com pequenos gestos mas é de iniciativa individual, como por exemplo arrumar a criança quando chegar, ter a gentileza de oferecer colocar no meu colo ou não, liberar um pouco mais de tempo dentro da UTI, para poder ficar um pouco mais de tempo, conversar, ouvir, colocar um lacinho de fita (M1L6)

A permissão do contato físico das mães com o $\mathrm{RN}$ foi algo citado como fator positivo, que contribuiu para a humanização do atendimento na UTIN.

[...] a enfermeira colocou a V. no meu colo e foi uma coisa completamente surpreendente pra mim porque eu nem sabia que eles podiam sair da isolete! (Risos). (M4L519)

Além disso, foram valorizadas situações em que os profissionais da saúde demonstravam uma relação mais próxima com os bebês e com as mães.

Então, tinha essa parte de humanização, lá era muito humano, muito gostoso. O banho deles era meio que uma farra, porque era a hora que eles saíam do leito, faziam alguma coisa diferente. (M6L1134)

A gente cortava cabelo na UTI! (Risos) Eu era a cortadora de cabelo da UTI! (Risos) O D. sempre teve o cabelo enroladinho e aí um dia a gente decidiu cortar e todo mundo gostou! Uma enfermeira falou: ahhh vamos passar a maquininha?!!E aí trouxe, me emprestou a maquininha dela.(M6L1140)

Mesmo nas situações mais difíceis, houve a possibilidade da percepção do atendimento humanizado, no qual a M1 narra o momento em que os profissionais da saúde respeitaram a necessidade da família de se despedir do bebê e proporcionaram condições para esta despedida.

Então ela desligou[...] claro, não desligou o respirador, mas desligou soro, remédio[...] não tinha mais porque nada daquilo naquele momento...tomar remédio[...] morrer tomando remédio?E trouxe pro colo, né?Trouxe claro que com oxímetro[...]claro que com a ventilação mecânica e tal...E aí ela ficou no meu colo[...] a equipe que não era necessária estar dentro da sala da UTI naquele 
momento[...] todo mundo saiu[...] quem era necessário ficou, quem não era necessário SAIU[...] Foi um ato extremamente respeitoso...e a gente ficou despedindo...(M1L197)

Couto e Praça (2009) 33 alertam para a necessidade das estratégias de promoção do vínculo entre profissionais e cuidadores ocorrerem ainda no ambiente hospitalar para que este processo de alta possa ser facilitado e se torne seguro, tanto para o recém-nascido prematuro, como para sua família. Estas situações estão intrinsecamente ligadas à autonomia da mãe no hospital, necessária para que os bebês tenham cuidadores aptos em domicílio, após o período de alta.

No relato abaixo, fica evidente a necessidade da mãe em participar dos cuidados ao bebê.

[...] e eles sempre permitiram isso, eu ia trocar uma fralda, às vezes na hora de tirá-la podia ficar um pouquinho com ela no colo, pesar o xixi, fazer parte desse tipo de rotina[...] empurrar o leite pela sonda, que era muito importante isso, porque eu tirava o leite, levava, todos os dias[...] era quase que a minha forma de ajudar né, de ficar de alguma forma como provedora da alimentação dela. (M4L549)

Em todos os relatos supracitados, os profissionais ao promoveremum atendimento individualizado, não seguindo apenas protocolos e sim observando as necessidades de cada indivíduo, contribuíram para estreitar o vínculo entre mãe-bebê, através da aproximação física entre ambos, e promoveram a capacitação da mãe para cuidar do bebê após alta hospitalar, através de ações educativas, como ensinar os cuidados básicos com o recém-nascido (troca de fralda, alimentá-lo, colocá-lo no colo, dar banho, dentre outros).

\section{CONSIDERAÇÕES FINAIS}

A presente pesquisa procurou situar o processo de humanização no campo das relações de poder onde foi possível verificar que a ocorrência da violência simbólica se constitui como um agravamento da desumanização em hospitais sob a perspectiva das mães acompanhantes de bebês internados em UTI's Neonatais.

Dessa forma, é possível identificar que o processo de humanização passa, sobretudo, pelo estabelecimento de relações menos assimétricas de poder entre a equipe hospitalar e as mães acompanhantes. Ainda que a compreensão da concepção da humanização seja processual, este é um caminho que necessita ser aprimorado constantemente, inclusive na Política Nacional de Humanização, a qual parte de conceitos e dispositivos que visam à reorganização dos processos de trabalho em saúde, propondo transformações nas relações sociais, que envolvem trabalhadores e usuários de saúde, na medida em que propõe transformações nas formas de prestar serviços à população, através da humanização do atendimento. De acordo com Santos-Filho (2007) ${ }^{34}$, a proposta da PNH coincide com os próprios princípios do SUS, enfatizando a necessidade de "assegurar atenção integral à população e estratégias de ampliar a condição de direitos e de cidadania das pessoas". Deste modo, é inegável o avanço que tal política representou à sociedade. No entanto, através dos relatos das entrevistadas, constatou-se que várias diretrizes da PNH não 
são efetivadas na prática hospitalar, tendo em vista que todas as subcategorias foram construídas baseadas nos documentos oficiais da Política Nacional de Humanização e no corpus da pesquisa.

A maioria dos relatos referentes aos fatores humanizadores fez menção ao atendimento individualizado. As mães valorizaram situações em que o caso de seus bebês foi tratado de acordo com suas especificidades, como por exemplo: deixar cortar o cabelo (dentro da UTIN) de um bebê que estava há muitos meses internado; deixar os pais se despedirem do bebê que estava em estado terminal, dentre outros. Esta evidência corrobora com estudos que demonstraram que os pacientes têm necessidade de um atendimento centrado em suas especificidades ${ }^{22,27-28}$.

Em relação aos fatores desumanizadores, além das situações referentes à falta de estrutura física do hospital, chamou a atenção o desrespeito aos direitos da criança, no que tange ao art.12 do ECA $(1990)^{29}$, que estabelece que "os hospitais devem proporcionar condições para a permanência em tempo integral de um dos pais ou responsável, nos casos de internação de criança ou adolescente". Podemos observar que o desrespeito aos direitos da criança, neste caso está ligado também às condições de estrutura física hospitalar. Pelo fato de seus bebês necessitarem de atendimento em unidades de terapia intensiva, as mães sujeitam-se às normas e condutas dos profissionais, conferindo legitimidade ao poder por eles exercido. Por isso, mesmo conscientes de seus direitos, sujeitam-se a situações em que eles não são efetivados.

A internação do neonato em UTI Neonatal desconstrói a imagem idealizada do filho e da identidade familiar. Os pais, impossibilitados de levarem o filho para casa, são obrigados a modificarem seus planos de vivenciar sua história junto ao novo membro da família. A experiência da mãe está intrinsecamente ligada à necessidade de construção da maternidade. Através dos relatos, foi possível perceber que as mães apresentam sentimentos conflitantes em relação aos cuidados do bebê; ao mesmo tempo em que sentem medo em realizar algum procedimento errado e causar dano ao filho, desejam autonomia para prestar os cuidados ao mesmo. Poder tocar o bebê, pegar no colo, trocar fralda, amamentar ou passar o leite pela sonda são experiências concretas de cuidado e, portanto, importantes para o vínculo mãe-bebê. Deste modo é evidente que o ambiente de UTIN precisa permitir e incentivar a participação da família nos cuidados ao bebê. Não apenas cumprindo as normas da PNH, de visita aberta e visita ampliada, e sim na criação efetiva de um ambiente que a família não se sinta secundária na vida do bebê. Assim, relações mais dialógicas entre usuários-profissionais de saúde, entendendo o usuário como capaz de exercer sua autonomia e sua capacidade protagonista, não apenas contribuem para o compartilhamento da responsabilidade pelo cuidado em saúde, e sim também por maior equilíbrio nas relações de poder no hospital.

Este estudo limitou-se à compreensão da experiência de um único membro da família - as mães dos bebês internados em UTIN, porém são necessárias pesquisas que tenham como foco a experiência de outros membros da família, de modo a analisar a interação entre seus diferentes atores sociais e o bebê internado na UTI Neonatal. 


\section{REFERÊNCIAS BIBLIOGRÁFICAS}

1. Deslandes SF. Análise do discurso oficial sobre a humanização da assistência hospitalar. Ciênc. Saúde Coletiva. 2004; 9(1):7-14.

2. Rugolo LMSS, Bottino J, Scudeler SRM, Bentlin MR, Trindade CEP, Perosa GB, et al. Sentimentos e percepções de puérperas com relação à assistência prestada pelo serviço maternoinfantil de um hospital universitário. Rev. Brasileira Saúde Materno Infantil [online]. 2004; 4(4):423-433.

3. Chalmers B. How often must we ask for sensitive care before we get it? Birth, 2002.

4. Vasconcelos MGL, Leite AM, Scochi CGS. Significados atribuídos à vivência materna como acompanhante do recém-nascido pré-termo e de baixo peso. Rev. Bras. Saude Mater. Infant. [online]. 2006; 6(1):47-57.

5. Dias GT, Souza JS, Franco LMC, Barçante TA. Humanização do cuidado na Unidade. Rev. Enferm. UFPE [online]. 2010; 4:941-947.

6. BRASIL. Ministério da Saúde. Atenção humanizada ao RN de baixo peso: método canguru. Brasília, DF, 2001.

7. Deslandes SF. Humanização: revisitando o conceito a partir das contribuições da sociologia médica. In: Deslandes, S. (org). Humanização dos cuidados em saúde: conceitos, dilemas e práticas. Rio de Janeiro: Fiocruz, 2006.

8. Ayres JRCM. Cuidados e Humanização das práticas de saúde. In: Deslandes, S. (org). Humanização dos cuidados em saúde: conceitos, dilemas e práticas. Rio de Janeiro: Fiocruz, 2006.

9. Foucault M. Microfísica do poder. Rio de Janeiro: Edições Graal, 1979.

10. Machado R. Por uma genealogia do poder. In: Foucault M. Microfísica do poder. Rio de Janeiro: Edições Graal; 1979. p VII-XXIII

11. Foucault M. A ordem do discurso. São Paulo: Loyola, 1996.

12. Bourdieu P. O poder simbólico. 10 ed. Rio de Janeiro: Bertrand Brasil, 2007.

13. Pereira WR. Poder, violência e dominação simbólicas nos serviços públicos de saúde. Texto Contexto Enferm. 2004; 13(3):391-400.

14. BRASIL. Ministério da Saúde. Programa Nacional de Humanização da Assistência Hospitalar. Secretaria de Assistência à Saúde. Brasília: Ministério da Saúde, 2000. 
15. Ministério da Saúde. Núcleo Técnico da Política Nacional de Humanização. Humaniza SUS Política Nacional de Humanização: documento para discussão. Brasília: Ministério da Saúde, 2003.

16. Alves CA, Deslandes SF, Mitre RMA. Challenges of humanization in the context of pediatric nursing care of medium and high complexity. Interface - Comunic. Saúde. Educ. 2009; 13(1):581-94.

17. Soares JCRS, Camargo Júnior KR. A autonomia do paciente no processo terapêutico como valor para a saúde. Interface - Comunic. Saúde Educ. 2007; 11(21):65-78.

18. Benevides R, Passos E. A humanização como dimensão pública das políticas de saúde. Ciência \& Saúde Coletiva. 2005; 10(3).

19. Benevides R, Passos E. Humanização na saúde: um novo modismo? Comunic, Saúde e Educ. 2005; 9(17):389-406.

20. Gallian DC, PondéLF, RuizR. Humanização, humanismos e humanidades - Problematizando conceitos e epráticas no contexto da saúde no Brasil. Rev. Internacional de Humanidades Médicas. 2012; 1(1):5-15.

21. Lacerda A, Valla V. Homeopatia e apoio social: repensando as práticas de integralidade na atenção e cuidado à saúde. In: PINHEIRO, R.; MATTOS, R. A. (Org.). Construção da Integralidade: cotidiano, saberes e práticas em saúde. Rio de Janeiro: ABRASCO, 2003. p. 169-196.

22. Barra DCC, Justina AD, Bernardes JFL, Vespoli F, Rebouças U, Cadete MMM. Processo de humanização e a tecnologia para o paciente internado em uma unidade de terapia intensiva. Rev. Mineira de Enfermagem. 2005; 9(4):341-347.

23. BRASIL. Ministério da Saúde. Secretaria de Atenção à Saúde. Núcleo Técnico da Política Nacional de Humanização. Acolhimento nas práticas de produção de saúde. 2. Ed. Brasília, Ministério da Saúde, 2010.

24. La Forgia GM, Couttolenc BF. Hospital Performance in Brazil. 1a edição. Washington: The World Bank, 2008.

25. Minayo MCS. O desafio do conhecimento: pesquisa qualitativa em saúde. São Paulo: Hucitec/ABRASCO, 1992.

26. Bardin L. Análise de conteúdo. Lisboa: Edições 70, 1977.

27. Vila VSC, Rossi LA. O significado cultural do cuidado humanizado em unidade de terapia intensiva: "muito falado, pouco vivido". Rev. Latino-Am. Enfermagem. 2002; 10(3):137-44. 
28. Medina RF, Backes VMS. A humanização no cuidado ao cliente cirúrgico. Rev. Bras. Enferm. 2002; 55(5):522-527.

29. BRASIL. Lei $N^{0} 8.069$, de 13 de julho de 1990. Dispõe sobre o Estatuto da Criança e do Adolescente, e dá outras providências. Diário Oficial da União, Brasília, DF, seção 1, p. 13563, jul. 1990. Disponível em: <http://www.planalto.gov.br/ccivil_03/leis/18069.htm>. Acesso em: 04 jan. 2016.

30. Machado R. Por uma genealogia do poder. In: Foucault M. Microfísica do poder. Rio de Janeiro: Edições Graal; 1992. P VII-XXIII.

Oliveira R, Maruyama SAT. Princípio da integralidade numa UTI pública: espaço e relações entre profissionais de saúde e usuários. Rev. Eletr. Enf. [Internet]., 2009; 11(2):375-382.

31. Klaus MH, Kennel JH. Pais/bebê - a formação do apego. Porto Alegre: Artes Médicas, 1993.

32. Couto FF, Praça NS. Preparo dos pais de recém-nascido prematuro para alta hospitalar: uma revisão bibliográfica. Esc Anna Nery Ver Enferm. 2009; 13(4):886-891.

33. Santos-Filho SB. Perspectivas da avaliação na Política Nacional de Humanização em Saúde: aspectos conceituais e metodológicos. Ciênc. saúde coletiva[online]., 2007; 12(4):999-1010.

34. Marshall RE. Neonatal Pain Associated with Caregiving Procedures. Pediatric Clinics of North America. 1989; 36(4):885-903.

35. Barker DP, Rutter N. Exposure to invasive procedures in Neonatal Intensive Care unit admissions. Archives of Disease in Childhood - Fetal and Neonatal Edition. 1995; 72: 47-48.

Artigo apresentado em 12/09/16

Artigo aprovado em 11/10/16

Artigo publicado no sistema em 0/0/16 